\title{
Thixotropy of Systems with Shear Thinning and Plastic Flow Behavior
}

\author{
Dimiter Hadjistamov \\ DECE GmbH, Helvetierstr. 15, Riehen 4125, Schweiz
}

\begin{abstract}
The definition of the thixotropy is a decrease in viscosity with time in shear and a subsequent recovery of viscosity after the shear deformation is removed. We used therefore start-up experiments with constant shear rates and can speak consequently of shear stress instead of viscosity. The shear stress increases sharply at the beginning of the stress growth experiment, passes an overshoot and begins to decrease up to the steady state shear stress. We can assume that a stress growth curve with an overshoot points out to thixotropic behavior. After the steady state shear stress is reached, the shear deformation is stopped, and the stress relaxation begins. It is to be expected that the shear stress will recover after the stress relaxation. Systems with shear thinning and plastic flow behavior were examined. The thixotropy is discussed in relation to the flow behavior. Stress growth experiments were performed with shear rates from the first Newtonian region and from the shear thinning region of the systems with shear thinning flow behavior. Stress start-up experiments were carrying out with shear rates from the first and second yield stress regions and from the transition section of a system with plastic flow behavior.
\end{abstract}

Key words: Thixotropy, rheopexy, systems with shear thinning flow behavior, systems with plastic flow behavior, time related flow behaviour.

\section{Introduction}

Mewis [1] ascertained that "At present, there exists a rather general agreement to call thixotropy the continuous decrease of apparent viscosity with time under shear and the subsequent recovery of viscosity when the flow is discontinued". Barnes, Hutton and Walters [2] defined the thixotropy as "gradual decrease of viscosity under shear stress followed by a gradual recovery of the structure when the stress rate is removed". Barnes [3] wrote "All liquids with microstructure can show thixotropy, because thixotropy only reflects the finite time taken to move from any one state of microstructure to another and back again, whether from different states of flow or to or from rest”.

Dullaert and Mewis [4] used model suspensions with fumed silica dispersed in a Newtonian fluid. After a sudden reduction of the shear rates, they

Corresponding author: Dimiter Hadjistamov, Ph.D., research fields: rheology, process development. studied the build-up curves during shear. The breakdown curves are also under shear investigated. Benchabane and Bekkour [5] investigated the rheological behavior of bentonite suspensions with different anionic additives. Labanda and Llorens [6] investigated colloidal dispersions with laponite in different molar concentrations of $\mathrm{NaCl}$. They used shear rate step procedure with different initial shear rates and shear rate hysteresis loops. Billotte et al. [7] used a pre-shear with a shear rate of 100 1/s for 1 min and a rest time of $2 \mathrm{~h}$ for the characterization of solder flux and pastes. They found that after a rest time of 2 $\mathrm{h}$, the viscosity increases acceptably slow or the structure is almost rebuilt.

Vermant et al. [8] measured nanocomposites of nanoclay in polypropylene. A stepwise reduction of the shear leads to build-up curves and a stepwise increase of the shear deformation-to breakdown curves. Ayyer and Leonov [9] described transient behavior of PA-6/clay nanocomposites. They founded that shear start-up experiments with shear rates of 0.05 
and 0.1 1/s lead to stress growth curves without a maximum and with shear rates of $0.5,1$ and 1.5 $1 /$ s - to stress growth curves with maximum. Zhao et al. [10] assumed the overshoot for wax-oil systems to be the yield point of the material.

The sentence of Mewis [1] "together with the related effect of yield stress, it (the thixotropy) constitutes probably the major remaining problem in theoretical rheology” seems to be still actual.

\section{Experimental}

The silicone oil M100000 is a polydimethylsiloxane (Bayer AG) with a weight average molecular weight of $104 \mathrm{~kg} / \mathrm{mol}$.

Araldite CW2215-7 (Huntsman AG) consists mainly of the epoxy resin Araldite GY260, calcium carbonate, silica and some additives. Araldite GY260 (Huntsman AG) is a diglycidyl ether of Bisphenol A with a viscosity of $14 \mathrm{~Pa} \cdot \mathrm{s}$ at $25^{\circ} \mathrm{C}$.

The rheological additive Bentone 27 is an organoclay with a density of $1.8 \mathrm{~g} / \mathrm{cm}^{3}$ and a bulk density of $0.34 \mathrm{~g} / \mathrm{cm}^{3}$ at $20^{\circ} \mathrm{C}$.

The suspensions Araldite CW2215-7 and 25 wt\% Bentone 27 in Araldite GY260 were prepared in a 1.5 $\mathrm{L}$ reactor with anchor stirrer $(100 \mathrm{rpm})$ at $40{ }^{\circ} \mathrm{C}$ in vacuum.

The rheological measurements were carried out with a Weissenberg rheogoniometer (WRG), model $\mathrm{R} 18$ at $25 \pm 0.2{ }^{\circ} \mathrm{C}$. The measurements begin after carefully loading and a rest time of $30 \mathrm{~min}$ to compensate the history effects.

We performed shear flow start-up experiments and a following stress relaxation. The shear stress $\tau$ is measured as a function of the time with constant shear rates $\gamma=$ const.

The points of the flow curves represent the steady state shear stress $\tau_{S}$ values from the stress growth experiments. Just after the steady state values are reached, the shear flow is stopped $(\dot{\gamma}=0)$ and the stress relaxation begins.

\section{Results and Discussion}

The thixotropy is a time dependent phenomenon connected with a decrease in viscosity with time under shear. The viscosity decreases, but the system must be sheared at first or a stress growth experiment must be performed. The stressing experiment is performed with a constant shear rate and the viscosity is proportional to the shear stress-one can speak of shear stress instead of viscosity.

The shear stress (or the viscosity respectively) increases in case of thixotropy sharp in the stress growth experiment, passes a maximum or an overshoot and then begins to decrease, but only to the steady state shear stress $\tau_{S}$ value (Fig. 1).

Barnes et al. [11] and Fernandes et al. [12] assumed the overshoot as a transition point between elastic and viscous regions. Barnes [3] described the region after the overshoot as a thixotropic breakdown. One can assume that a characteristic for the thixotropy is the overshoot of the stress-growth curve in the stressing experiment.

After the steady state shear stress is reached, one must perform the stress relaxation. The viscosity must recover after a rest period, but it is the same problem-to measure the viscosity one must perform once more a stressing experiment. This second stress growth experiment will not be discussed in this contribution.

The rheopexy is, as contrary to thixotropy, the increase in shear stress or viscosity with time in shear.

\subsection{Systemswith Shear Thinning Flow Behaviour}

The systems with shear thinning flow behavior show a first Newtonian region, a shear thinning region and sometimes a second Newtonian region.

\subsubsection{Silicone Oil M100000}

The viscosity curve of the silicone oil M100000 (Fig. 2) exhibits shear thinning flow behavior [13]. This silicone oil has a first Newtonian region with a zero-shear viscosity of $100 \mathrm{~Pa} \cdot \mathrm{s}$ up to the onset of shear thinning at the shear rate of $151 / \mathrm{s}$. 


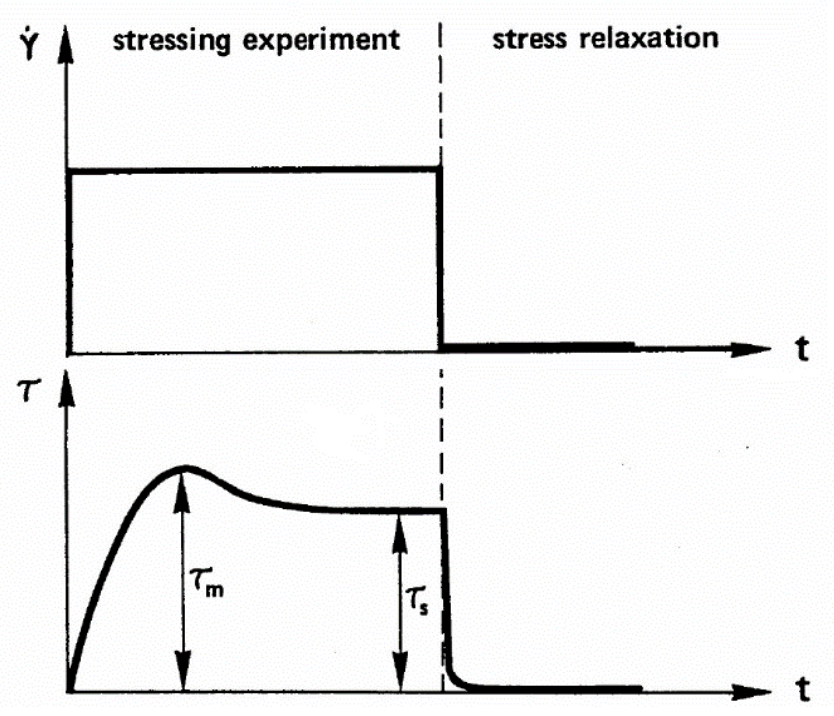

Fig. 1 Schematically stressing experiment.

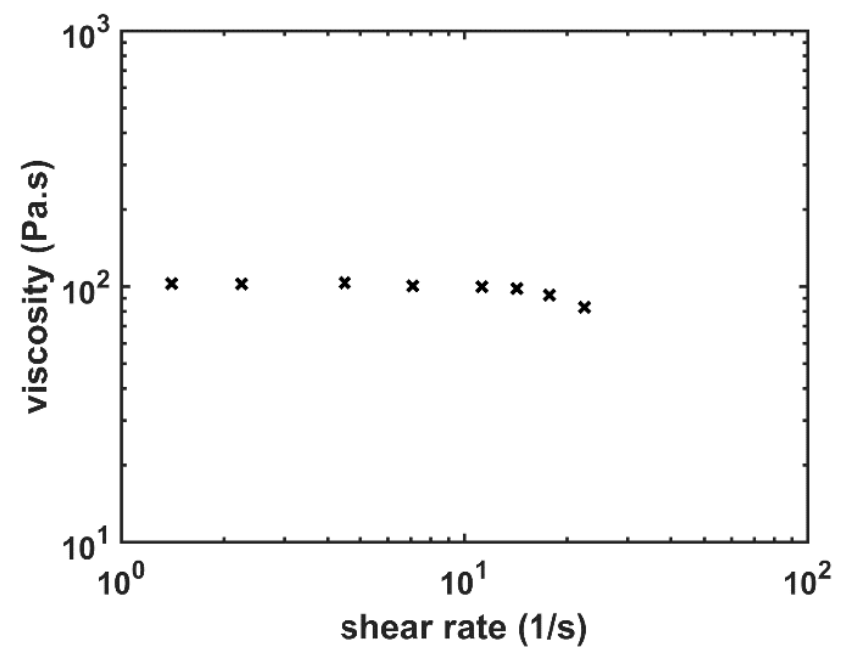

Fig. 2 Viscosity curve of the silicone oil M100000 (WRG, plate-plate, $25 \pm 0 .{ }^{\circ} \mathrm{C}$ ).

A start-up curve without a maximum is obtained in stress growth experiments with the shear rate of 11.25 1/s (Fig. 3) from the first Newtonian region. The shear stress immediately reaches the steady state shear stress. In the first Newtonian region the molecules can compensate the shear deformation and the shear stress remains proportional to the shear rate.

The stress growth curve with $14.21 / \mathrm{s}$, or near the onset of shear thinning, exhibits the first small overshoot (Fig. 3). This is the first sign of decrease of the shear stress or viscosity respectively and the first notice of thixotropy. One can determine the onset of shear thinning for homogeneous shear thinning systems from the first sign of an overshoot of the start-up curve.

The stressing experiment with the shear rate of 17.8 1/s (Fig. 3) from the shear thinning region (Fig. 2) causes a more pointed maximum. The overshoots of the stress growth curves with shear rates from the shear thinning region point out that the system has thixotropic behavior in this region.

No residual shear stress is observed [13] in the stress relaxation after cessation of the stress deformation (Fig. 3).

3.1.2 Araldite CW2215-7

The suspension Araldite CW2215-7 exhibits shear 
thinning flow behavior. The first Newtonian region has a zero-shear viscosity of $260 \mathrm{~Pa} \cdot \mathrm{s}$ (Fig. 4). The onset of shear thinning appears at $0.031 / \mathrm{s}$.

As expected, the shear flow start-up experiments with shear rates from the first Newtonian region show stress growth curves without maximum. The shear flow start-up experiment with the shear rate of 0.045 $1 / \mathrm{s}$, near the onset of shear thinning, but from the shear thinning region also shows a stress growth curve without maximum.

The first sign of a stress growth curve with an overshoot is established at a shear rate of 0.14 1/s (Fig. 5), i.e., a shear rate from the shear thinning region.
Experiments with higher shear rates from the shear thinning region (Fig. 5) lead also to stress growth curves with an overshoot or thixotropy. Higher shear rates cause a pronounced bigger overshoot and appear at a smaller time.

Letwimolnun et al. [14] found for organoclay nanocomposites that "the overshoots occurred at the same strain of about 1.7".

The shear flow start-up experiments of systems with shear thinning flow behavior with shear rates from the first Newtonian region exhibit stress growth curves without maximum and the shear stress immediately reaches the steady state value (Fig. 6). The

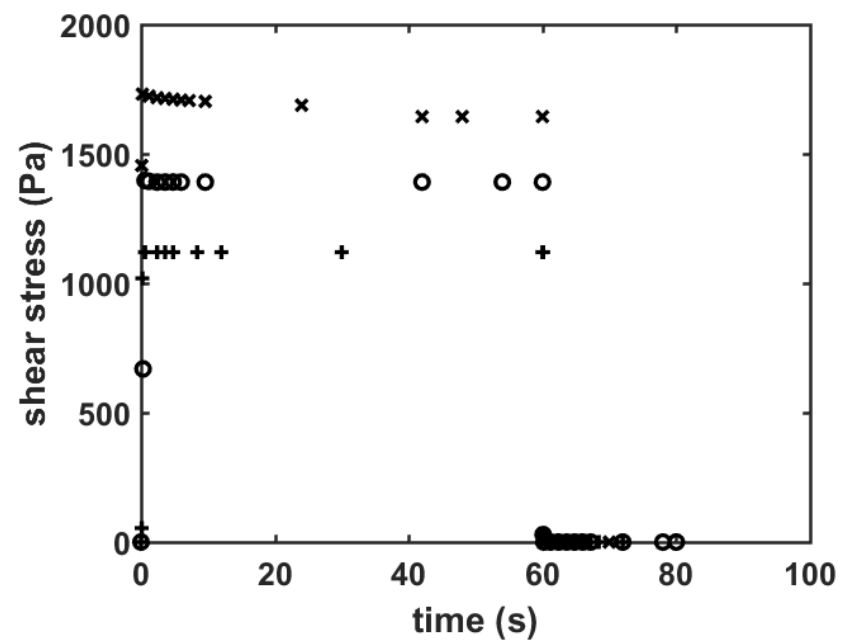

Fig. 3 Stress growth curves of the silicone oil M100000 with (+) 11.25 1/s, (o) 14.2 1/s, (x) 17.8 1/s (WRG, cone-plate $6^{\circ}$, $25 \pm$ $\left.0.2{ }^{\circ} \mathrm{C}\right)$.

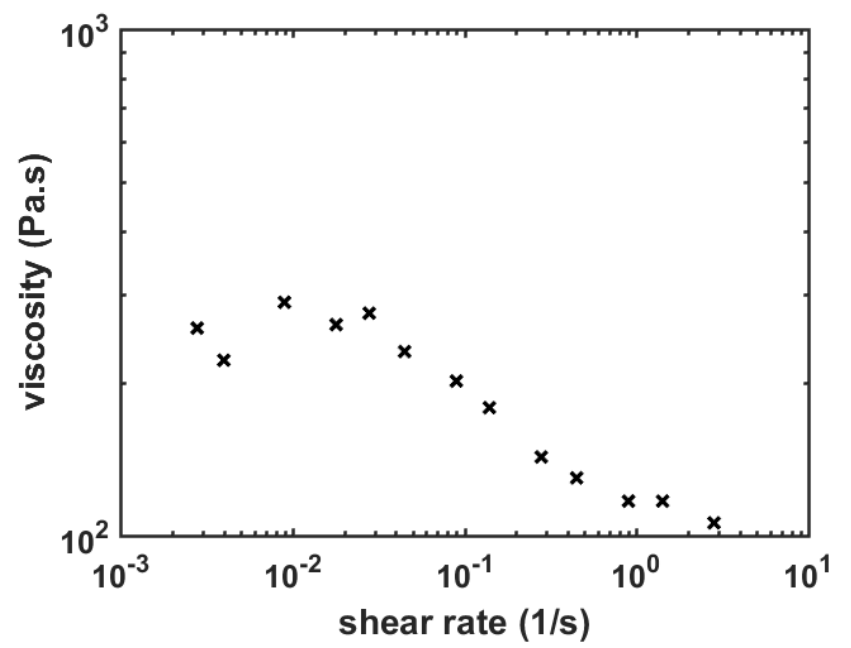

Fig. 4 Viscosity curve of Araldite CW221-7 (WRG, cone-plate $4^{\circ}, 25 \pm 0.2{ }^{\circ} \mathrm{C}$ ). 


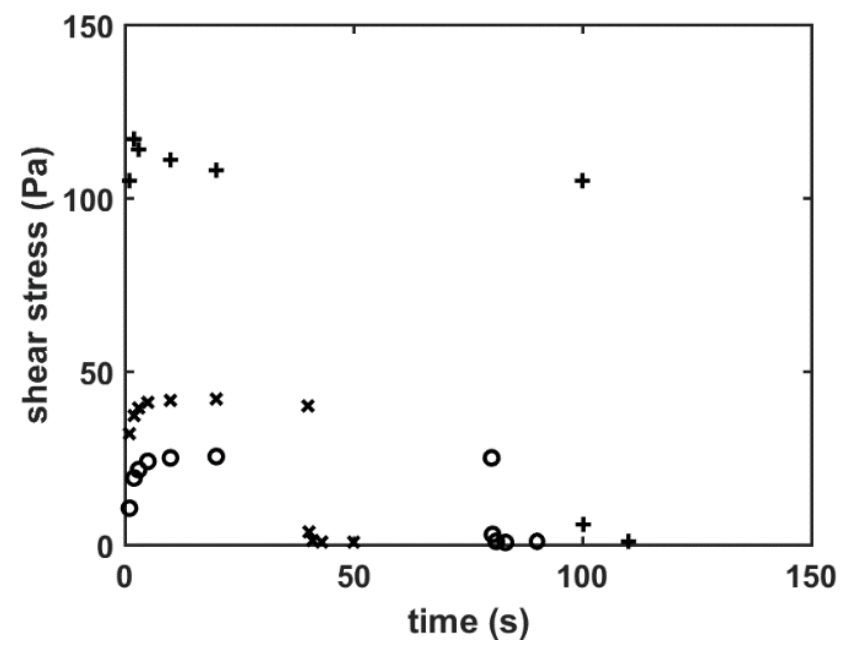

Fig. 5 Shear flow start-up experiments of Araldite CW2215-7 with shear rates of (o) 0.14 1/s, (x) 0.28 1/s, (+) 0.9 1/s (WRG, cone-plate $4^{\circ}, 25 \pm 0.2{ }^{\circ} \mathrm{C}$ ).
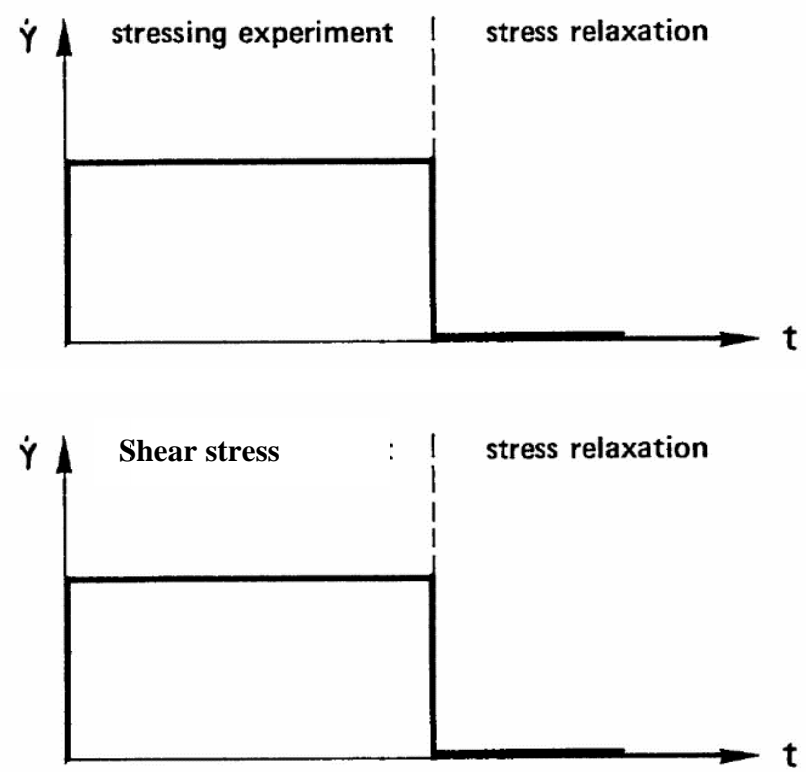

Fig. 6 Schematically stressing experiments with shear rates from the first Newtonian region.

shear stress is proportional to the shear rate. One can not expect thixotropic or rheopexy behavior in this region.

The measured suspensions, as systems with shear thinning flow behavior, show an overshoot or thixotropic behavior in stressing experiments with shear rates from the shear thinning region (Fig. 1).

The shear stress declines towards the zero point on relaxation—no residual shear stress is observed after the cessation of the shear deformation in the first Newtonian region and in the shear thinning region
(Figs. 3 and 5). No remaining structure exists after the shear flow start-up experiments that can oppose against the elastic returned springing of the strip bar to the starting point.

\subsection{Suspension with Plastic Flow Behaviour}

The main feature of the systems with plastic flow behavior is the existence of a 3D-structure that can lead to a yield stress.

We extended the definition of the yield stress [15] and assumed that there are according to the value of 
the relative residual shear stress three different kinds of yield stresses:

- systems with a yield stress at the yield point, which indicates the limit of elastic behavior and the beginning of plastic behavior or the stress at which a material begins to deform plastically, according to the existing definition. At the stress relaxation this will be the shear stress at a relative residual shear stress (the ratio of residual shear stress to the steady state shear stress) of approx. 1.

- most of the rheological systems do not reach the yield point, but have a 3D-structure with a relative residual shear stress more than 0.30 at low shear rates.

- for practical purposes, the rheological systems with a weak 3D-structure, but with a relative residual shear stress more than 0.1 at low shear rates.

3.2.1 Suspension with 25 wt $\%$ Bentone 27 in Araldite GY260

The first point of the relative residual stress curve of the system with $25 \mathrm{wt} \%$ Bentone 27 (Fig. 7) has a value of 0.54 , which points to a strong $3 \mathrm{D}$-structure [16] and plastic flow behavior with yield stress.

We assume that the system with $25 \mathrm{wt} \%$ Bentone 27 exhibits two yield stresses [16]. The flow curve can not be measured at lower shear rates and a pronounced first yield stress region is not observed. Therefore, the first yield stress is determined by extrapolating of the flow curve to the $y$-axis with $130 \mathrm{~Pa}$ (Fig. 8).

The system has a pronounced second yield stress region, ascertained with $600 \mathrm{~Pa}$ from the flow curve (Fig. 8) and from the relative residual shear stress curve (Fig. 7). Rapid drop of the relative residual shear stress occurs in the region of the second yield stress section (Fig. 7).

The section between the two yield stress regions, between 0.001 and $0.0151 / \mathrm{s}$, is the transition section. It is observed a slowly decrease of the relative residual shear stress (Fig. 7) in this region. A physical change of the structure occurs in this transition region.

This suspension exhibits a rather complicated time related flow behavior. Fig. 9 shows the start-up experiments with shear rates from the first yield stress region $(0.000481 / \mathrm{s}$ and $0.000961 / \mathrm{s})$.

The stress growth curves of these experiments pass through a maximum before reaching the steady state values. The overshoots of these stressing experiments suggest thixotropic behavior.

The start-up experiment with a shear rate from the transition section $(0.0031 / \mathrm{s})$ shows a very interesting stress growth curve (Fig. 10). It begins with a small maximum and a following increase in the shear stress up to the steady state shear stress.

The shear flow start-up experiments with the shear rates $0.00481 / \mathrm{s}$ and $0.0151 / \mathrm{s}$, also from the transition

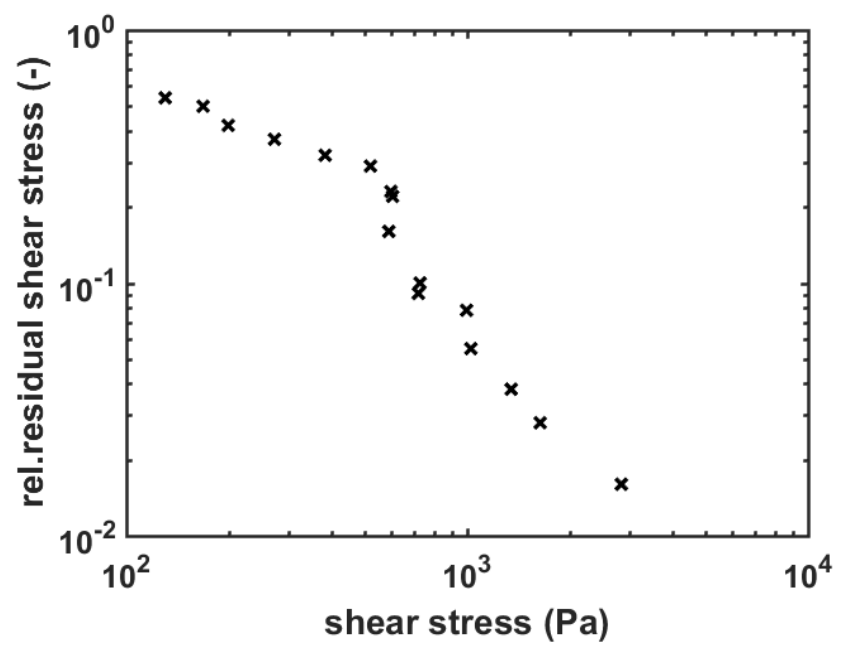

Fig. 7 Relative residual shear stress curve of the suspension with $25 \mathrm{wt} \%$ Bentone 27 in Araldite GY260 (WRG, cone-plate $\left.6^{\circ}, 25 \pm 0.2^{\circ} \mathrm{C}\right)$. 


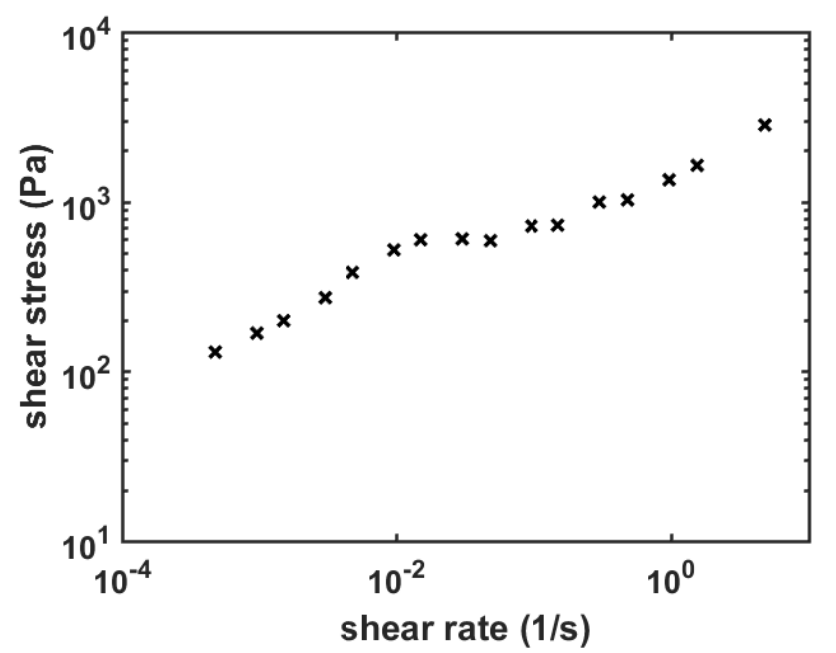

Fig. 8 Flow curve of the suspension with 25 wt $\%$ Bentone 27 in Araldite GY260 (WRG, cone-plate $6^{\circ}, 25 \pm 0.2^{\circ} \mathrm{C}$ ).

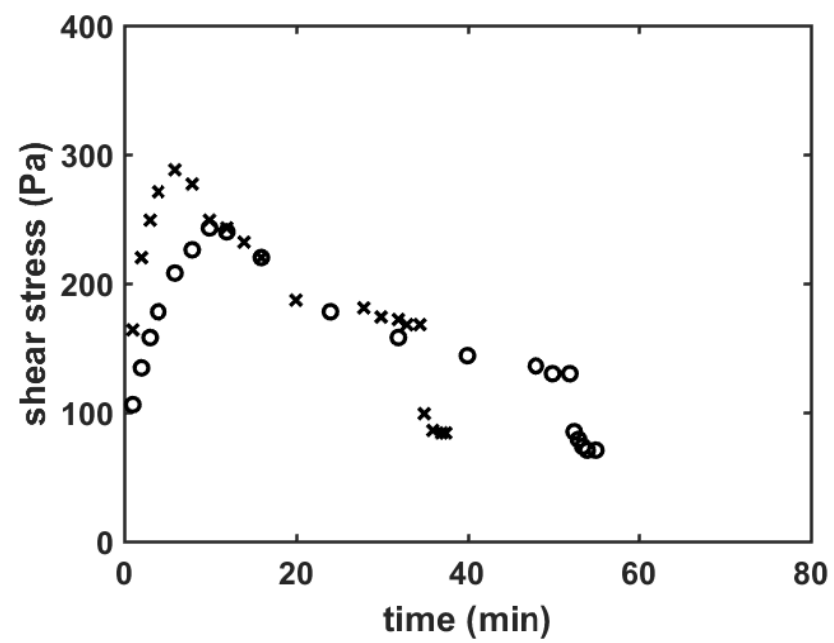

Fig. 9 Shear flow start-up experiments of 25 wt \% Bentone 27 in Araldite GY260 with shear rates of (o) 0.00048 1/s, (x) 0.00096 1/s (WRG, cone-plate $6^{\circ}, 25 \pm 0.2^{\circ} \mathrm{C}$ ).

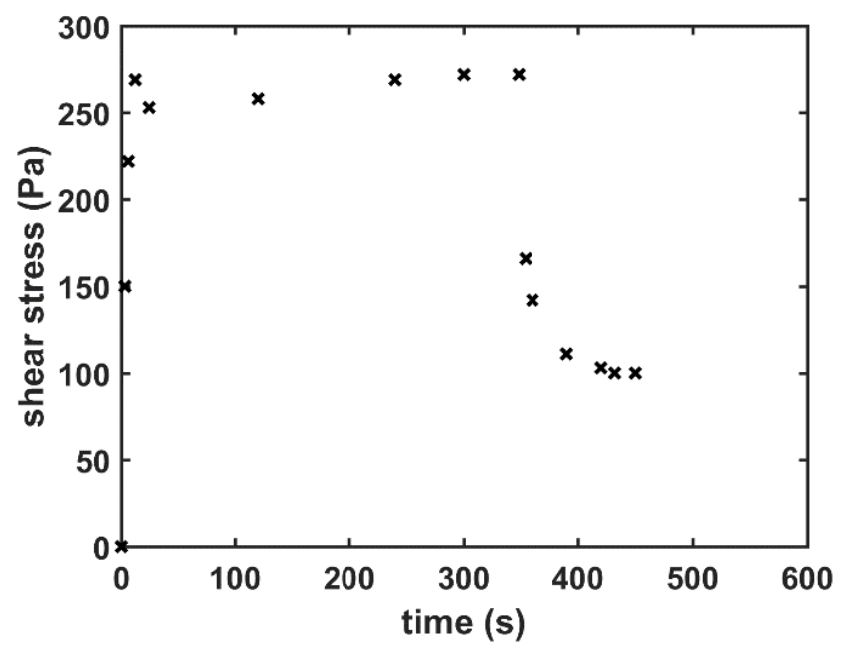

Fig. 10 Start-up experiments of 25 wt \% Bentone 27 in Araldite GY260 with a shear rate of 0.003 1/s (WRG, cone-plate $6^{\circ}$, $25 \pm 0.2^{\circ} \mathrm{C}$ ). 
section (Fig. 8), display stress growth curves without maximum (Fig. 11). That points out to rheopexy behavior. The shear stress increases up to a steady state shear stress.

The subsequent following stress relaxation leads to relative residual shear stresses of 0.32 and 0.23 (Fig. 11) respectively.

The first normal stress difference curve (Fig. 12) exhibits a yield normal stress region with $105 \mathrm{~Pa}$. It follows a deep decrease in the first normal stress difference between $0.0048 \mathrm{1} / \mathrm{s}$ and $0.0151 / \mathrm{s}$, up to minus values (-10 Pa) for $0.00961 / \mathrm{s}$ and $-7 \mathrm{~Pa}$ for
$0.0151 / \mathrm{s}$. This region corresponds closely to the transition section of the flow curve (Fig. 8). It is obviously a connection between the rheopexy behavior and the decrease in the first normal stress difference. A reorganisation of the structure takes place in the transition section with a slowing down of the relative residual shear stress decrease (Fig. 7) and a sharp decrease in the first normal stress difference (Fig. 12).

The shear flow start-up experiment with a shear rate of $0.031 / \mathrm{s}$ from the second yield stress region again presents a stress growth curve with an overshoot

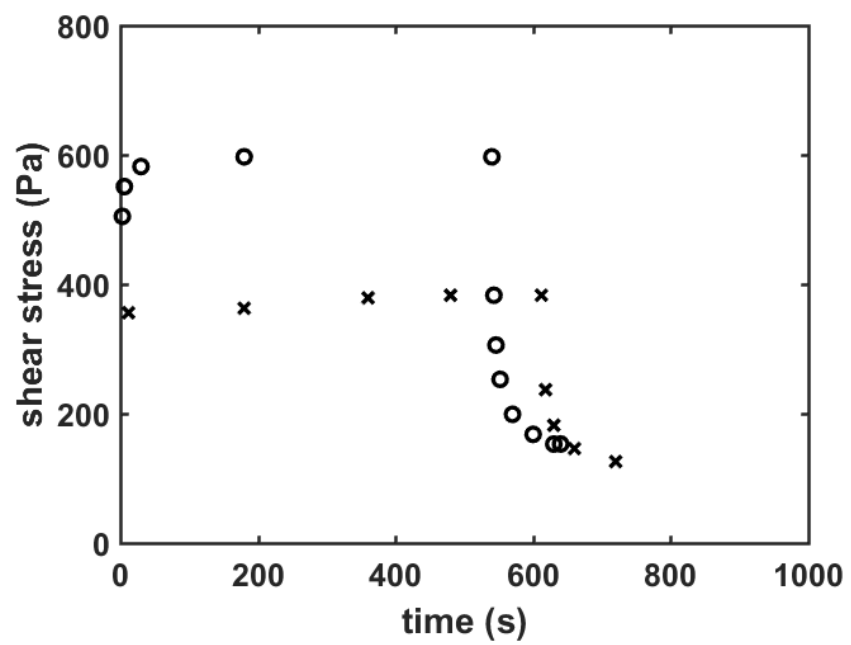

Fig. 11 Start-up experiments of $25 \mathrm{wt} \%$ Bentone 27 in Araldite GY260 with shear rates of (x) 0.0048 1/s and (o) $0.0151 / \mathrm{s}$ (WRG, cone-plate $6^{\circ}, 25 \pm 0.2^{\circ} \mathrm{C}$ ).

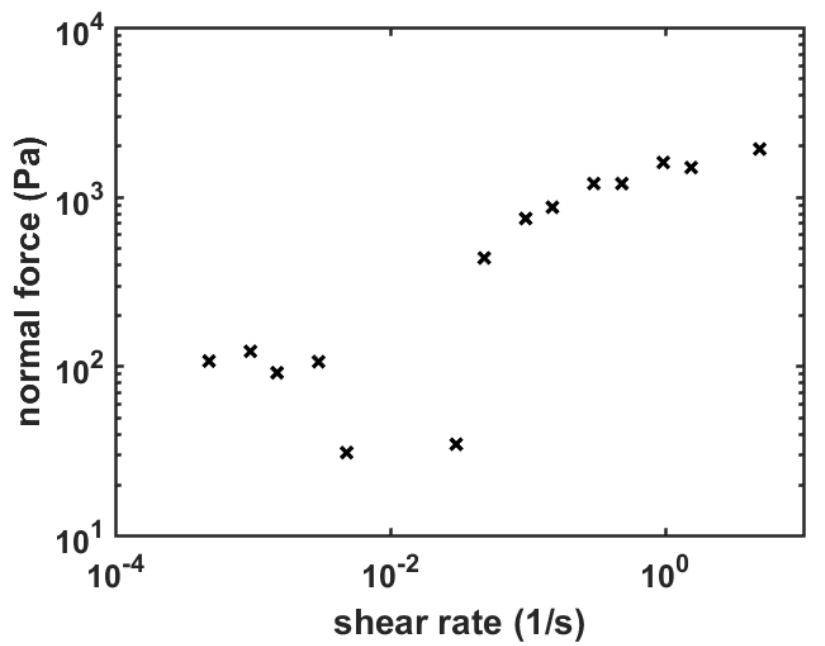

Fig. 12 First normal stress difference curve of the suspension with 25 wt\% Bentone 27 in Araldite GY260 (WRG, cone-plate $6^{\circ}, 25 \pm 0.2^{\circ} \mathrm{C}$ ). 


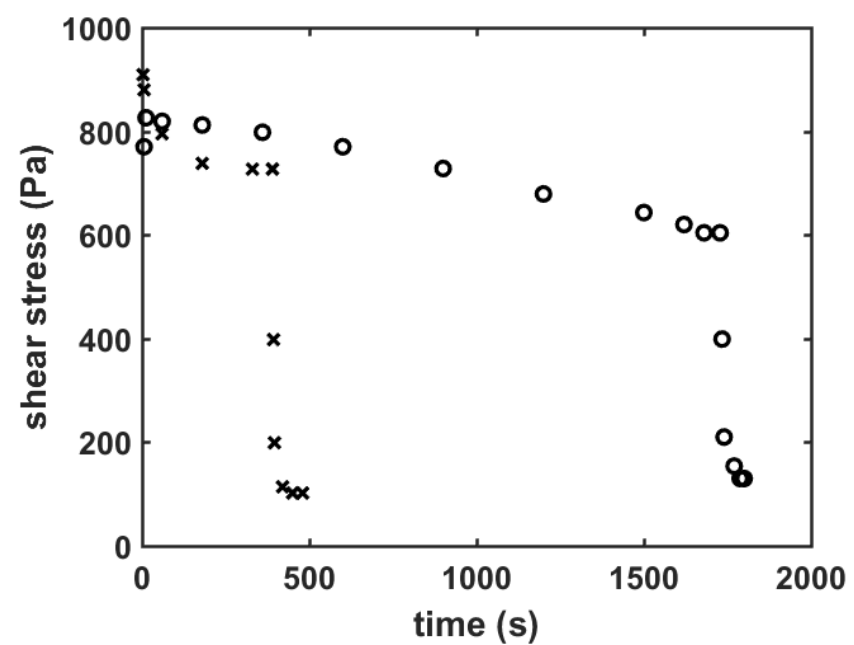

Fig. 13 Shear flow start-up experiments of 25 wt\% Bentone 27 in Araldite GY260 with shear rates of (o) 0.03 1/s and (x) $0.151 /$ s (WRG, cone-plate $6^{\circ}, 25 \pm 0.2^{\circ} \mathrm{C}$ ).

(Fig. 13). Start-up experiments with higher shear rates (0.15 1/s) also indicate stress growth curves with an overshoot (Fig. 13) or thixotropic behavior.

The system with $25 \mathrm{wt} \%$ Bentone 27 exhibits thixotropy as well as rheopexy. Start-up experiments with an overshoot, or thixotropic behavior, are observed with shear rates from the first yield stress region. It follows stress growth curves without maximum or rheopexy with shear rates from the transition section. Start-up experiments with shear rates from the second yield stress region and higher shear rates lead to stress growth curves with an overshoot or thixotropic behavior.

\section{Conclusions}

The systems with shear thinning flow behavior exhibit start-up curves without maximum at shear rates from the first Newtonian region. The shear stress immediately reaches the steady state values in the start-up experiments. It is not possible to speak about thixotropy or rheopexy in the first Newtonian region.

Start-up experiments with shear rates from the shear thinning region lead to an overshoot with decrease in shear stress or thixotropic behavior. The systems with shear thinning flow behavior exhibit thixotropic behavior only in the shear thinning region. The decrease in the shear stress is not unlimited, and it occurs certainly up to the steady state shear stress, which depends on the used shear rate.

The system with $25 \mathrm{wt} \%$ Bentone 27 in the epoxy resin Araldite GY 260 exhibits plastic flow behavior with two yield stresses. The stress growth experiments with shear rates from the first yield stress region show an overshoot or thixotropic behavior.

The start-up experiments with shear rates from the transition section lead to an increase in the shear stress with time up to the steady state shear stress or exhibit rheopexy. The rheopexy relates to the decrease in the first normal stress difference in this region. This is a consequence of the rearrangement of the structure in the transition sections.

Stress growth experiments with shear rates from the second yield stress region and higher shear rates indicate once more an overshoot or thixotropic behavior.

It is not possible to maintain that a whole system shows thixotropy. We can speak of thixotropy only in a specified region of a system:

- with shear thinning flow behavior-in the shear thinning region;

- with plastic flow behavior-in the first and second yield stress regions and in the following regions.

Rheopexy was found only in the transition section 
of the system with plastic flow behavior.

The form of the stress growth curve reflects the reaction of the structure in the stressing experiment with the used shear rate. There are three kinds of stress growth curves:

- the shear stress reaches immediately the steady state value, when the shear stress is proportional to the used shear rate, and it is not possible to speak of thixotropy or rheopexy;

- the start-up curve shows an overshoot or thixotropy, when the used shear rate leads to a distortion of part of the structure;

- the start-up curve exhibits at the used shear rate on increase of the shear stress.

It happens that a rearrangement of the structure or rheopexy is observed.

\section{References}

[1] Mewis, J. 1979. "Thixotropy-A General Review." J. Non-Newt. Fluid Mech. 6: 1-20.

[2] Barnes, H. A., Hutton, J. F., and Walters, K. 1989. An Introduction to Rheology. Amsterdam: Elsevier.

[3] Barnes, H. A. 1997. “Thixotropy-A Review.” J. Non-Newt. Fluid Mech. 70: 1-33.

[4] Dullaert, K., and Mewis, J. 2005. "Thixotropy: Build-Up and Breakdown Curves during Flow.” J. Rheol. 49: 1213-30.

[5] Benchabane, A., and Bekkour, K. 2006. "Effects of Anionic Additives on the Rheological Behaviour of Aqueous Calcium Montmorillonite Suspensions.” Rheol. Acta 45: 425-43.

[6] Labanda, J., and Lorens, J. 2006. “A Structural Model for
Thixotropy of Colloidal Dispersions.” Rheol. Acta 45: 305-14.

[7] Billotte, C., Carreau, P. J., and Heuzey, M. C. 2006. "Rheological Characterization of a Solder Paste for Surface Mount Applications.” Rheol. Acta 45: 374-86.

[8] Vermant, J., Ceccia, S., Dolgovskij, M. K., Maffettone, P. L., and Macosko, C. W. 2007. "Quantifyingdispersion of Layered Nanocomposites via Melt Rheology.” J. Rheol. 51: 429-50.

[9] Ayyer, R. K., and Leonov A. I. 2004. "Comparative Rheological Studies of Polyamide-6 and Its Low Loaded Composite Based on Layered Silicates.” Rheol. Acta 43: 283-92.

[10] Zhao, Y. L., Kumar, K., Ali. H., Salieva, J., and Sjöblom, J. 2012. "Gelation and Breakage Behavior of Model Wax-Oil Systems: Rheological Properties and Model Development.” Ind. Eng. Chem. Res. 51: 8123-33.

[11] Barnes, H. A., and Nguyen, Q. D. D. 2001. "Rotating Vane Rheometry-A Review.” J. Non-Newt. Fluid Mech. 98: 1-14.

[12] Fernandes, R. R., Andrade, D. E. V., Franco, A. T., and Negredo, C. O. R. 2016. "Correlation between the Gel-Liquid Transition Stress and the Storage Modulus of the Oil-Based Drilling Fluid.” J. Non-Newt. Fluid Mech. 231: 6-10.

[13] Hadjistamov, D. 2008. "Determination of the Onset of Shear Thinning of Polydimethylsiloxane.” J. Appl. Pol. Sci. 108: 2356-64.

[14] Letwimolnun, W., Vergnes, B., Ausias, G. and Carreau, P. J. 2007. "Stress Overshoots of Organoclay Nanocomposites in Transient Shear Flow.” J. Non-Newt. Fluid Mech. 141: 167-79.

[15] Hadjistamov, D. 2018. "Determination of the Yield Stress of Disperse Systems.” J. Mat. Sci. Eng. A 8: 147-54.

[16] Hadjistamov, D. 2010. "Model Suspensions with Rheological Additives: System with Plastic Flow Behavior.” Pol. Eng. Sci. 811-8. 